http://dx.doi.org/10.12795/PH.1990.v05.i01.16

\title{
Las denominaciones del hecho alemán
}

\author{
José Ma Piñán San Miguel
}

\section{1. «Deutsch» como gentilicio atípico}

Cuando en español hablamos de un gentilicio nos referimos a un constituyente adjetivo que denota la pertenencia a un pueblo o nación. Se trata, salvo casos de fuerte implicación histórica o de sinónimos con distintas connotaciones, de derivaciones morfémicas añadidas al formante léxico que, precisamente, designa a ese pueblo o nación.

De esta forma español evidencia su procedencia de España como americano la suya de América. No puede diferenciarse en este sistema lingüístico si la referencia del adjetivo es personal, de lengua o de otra entidad. Una mayor precisión referencial tendríamos en alemán cuando, a partir de Spanien ${ }^{1}$, se distingue Spanier (persona), Spanisch (lengua) y spanisch (genérico).

En este sentido no puede hablarse en alemán para su propia denotación de un gentilicio por derivación, puesto que la serie Deutschland, Deutscher, Deutsch, deutsch tiene un origen y sigue una línea de derivación opuesta a la aquí considerada. Pero esta peculiaridad no estriba en las características del sistema -que en otros casos puede hacer p. ej: Russe-->russisch-->Russisch-->Rußland- sino en la originalidad e historia del adjetivo que aquí nos ocupa, claramente distintas del resto de los gentilicios.

Quizá también como en ninguna otra nación la peculiar configuración tribal, histórica y cultural del hecho alemán se refleja en las denominaciones con que otras naciones y otras lenguas se refieren a él.

${ }^{1}$ Sigo la línea de derivación propia del español. En alemán se considera habitualmente al gentilicio personal como origen de la serie de derivaciones. 


\section{La etimología de «deutsch»}

La buena documentación en distintas lenguas del tronco germánico permiten, en este caso, despejar el alto grado de especulación que afectaría a germ. * peudo, como a cualquier otra forma léxica inducida. Este término hipotético encuentra su refrendo en got. piuda, as. thioda, ags. peod y ahd. diota/diot (mhd. diet)2

La derivación adjetiva sería germ. * peudiska y documentados ahd. diutisc, as. thiudisk, ags. peodisc, got. piudisko.

El significado viene dado en todos los casos por la referencia al pueblo o al grupo tribal propio, pero en una utilización deíctica, de alcance impreciso y cuya mayor explicitud se produce por oposición a las etnias del entorno a las que se engloba bajo ahd. walhisc (nhd. welsch).

Este uso distintivo se muestra en la que tal vez sea la primera aparición documentada del adjetivo: "Wenn Wulfila $\varepsilon \dot{\theta} v \imath \kappa \omega$ s «heidnisch» durch das Adverb piudisko wiedergegeben hatten, so versteht sich das in genauer Analogie aus seiner Erfahrung von dem Unterschied zwischen dem christlichen Griechen- und seinem in der Hauptsache noch heidnischen Gotenvolk» ${ }^{3}$.

Como decía, este valor deíctico y no referencial concreto se manifiesta en la presencia del formante léxico en todas aquellas lenguas tribales que proceden del germánico y, según los ejemplos documentados se decanta en su forma neutra y en sintagma preposicional a significar «en la lengua del pueblo» (respectivo), am klarsten in dem ags. neutr. ge peóde, welches geradezu lingua ausdrückt y respectivamente tô thiothe en afries., githiuti en ahd. githiudo en as. (Heliand), ze tiute en mhd. e in dietsche en mndl.

$\mathrm{Su}$ valor referencial, distinto en cada caso, asume el significado de «en frisio», «en sajón», «en neerlandés»...

${ }^{2}$ Ver abreviaturas al final.

${ }^{3}$ «Si Wulfila había traducido $\varepsilon$ $\theta v \imath \kappa \omega \varsigma \zeta$ «pagano» por el adverbio piudisko debe ser entendido en exacta analogía a su experiencia de la distinción entre la comunidad cristiana griega y su pueblo godo, mayoritariamente aún pagano», Tschirch, F. pp. 166-167.

4 «Como ejemplo más claro en el neutro anglosajón "gepeode" que signfica, justamente, lengua». Grimm, J.- Excurs über Germanisch und Deutsch, pp. 1-16 en Eggers, H.- «Der Volksname Deutsch», p. 11. Vid también pp. 9-14.

${ }^{5}$ Como identificación en otro ámbito de «deutsch» y «fränkisch» puede traerse a colación el siguiente pasaje:

«Das Wort "Deutsch" bedeutet anfänglich nicht die Sprache aller nicht romanisierten Germanenstämme. Es bedeutet im Gegenteil mit Betonung die Sprache der nicht romanisierten Franken links wie rechts, besonders aber links des Rheines». (..) «Deutsch heißt fränkisch, und zwar die Sprache, die Karl der Große selbst spricht. Der Frankenkaiser sagt in seiner pompösen Gesetzgeberurkunde den Italienern: quod nos theudisca lingua herisliz dicimus, und 811 steht in einer Wiederholung dieses Gesetzes quod Franci dicunt herisliz.

Aus diesen beiden Urkunden ist also die Kongruenz von fränkisch und deutsch bewiesen, daß Karl, der Franke, speziell seine eigene Sprache die deutsche nennt».

(«La palabra "deutsch" no significa en sus comienzos la lengua de todas las tribus germanas no romanizadas. Al contrario, significa y con énfasis la lengua de los francos no romanizados a izquierda y 


\section{El reflejo popular en transcripción latina: «Theodiscus»}

Volviendo al adjetivo en cuestión en ahd. ha de considerarse que la posible evolución germ. * peudiska--> ahd. * peudisk/ peodisk--> diutisc es una inferencia de las transcripciones latinas de época. Su aparición documental en ahd. se produce dos siglos después de que lo hiciera en latín y adopta tanto ortográfica como referencialmente la perspectiva de éste, por lo que al entronque con las formas germánicas es sólo indirecto. Como consideraba más arriba, la referencia a la lengua del pueblo se hace por oposición a la lengua culta que usan clérigos y nobles. En la mención que estos últimos hacen de theodisca lingua no excluye Grimm la connotación de bárbara y vulgar en una lengua vernácula falta de expresión escrita, esencialmente por falta de la capacidad para ello en quienes la utilizan.

Aunque según varios autores, la primera referencia data del año $786^{6}$, se cuenta en general con los Annales regni Francorum del 788 como primer documento en que se menciona el término. En el juicio al que Tassilo, duque de Baviera, es sometido por Carlomagno, se le imputa deserción del ejército imperial, «quod theodisca lingua herislìz dicitur», fórmula que se repite en sucesivos protocolos capitulares para referirse a términos populares inexistentes en latín.

Pero es en el terreno de la misión apostólica donde con más frecuencia se recomienda el uso de ambas lenguas a fin de facilitar la comprensión del mensaje por el pueblo. En el Sínodo de Tours (813) se prescribe «ut easdem omelias quisque aperte transferre studeat in rusticam Romanam linguam aut Theotiscam, quo facilius cuncti possint intellegere quae dicuntur»?.

De nuevo en el ámbito político, encontramos en el 842 la oposición diutiscwalhisc no referida esta vez al latín ni al celta o eslavo, sino a la romana rústica del franco occidental.

La nueva situación responde a la evolución lingüística a ambos lados del Rin en el apogeo del imperio carolingio (800). Al este han aparecido formas dialecto-tribales para el bávaro, el franco oriental, el sajón, el alemánico y el renano-franco, consolidadas en un terreno conquistado de escasa romanización previa, por lo que, con ligeras modificaciones, se han impuesto sin dificultad en sus respectivas zonas.

derecha, pero sobre todo a la izquierda del Rin. (...) "Deutsch" significa "franco" y, en concreto, la lengua que habla el mismo Carlomagno. El emperador franco dice a los italianos en su pomposo edicto del 801: lo que llamamos "herisliz" en lengua theudisca, y en el 811 aparece en una repetición de esta ley: lo que los francos llaman "herisliz" Ambos documentos prueban la congruencia de franco y "deutsch" y prueban aún más, que Carlos, el Franco, llama explícitamente "deutsch" a su propia lengua). Rosenstock, E.- Unser Volksname Deutsch und die Aufhebung des Herzogtums Bayern, pp. 32-102 en Eggers, H. "Der Volksname...", passim 43-45»].

6. Se trata de un relato carolingio sobre la misión de Georg von Ostia en territorio anglosajón, donde «...capitula perlecta sunt et tam latine quam theodisce, quo omnes intellegere potuissent...» Sin embargo el relato está datado en Trier en el 965 . Vid. Weisgerber, L.- Theudisk. Der deutsche Volksname un die westliche Sprachgrenze, pp. 103-165 en Eggers, H. «Der Volksname...», especialmente p. 130 y sig.

${ }^{7}$ Monumenta Germaniae, Concilia II, 1, p.288. cit. en Brinkmann, H.- Theodiscus. Ein Beitrag zur Frühgeschichte des Namens «Deutsch». pp. 183-208 en Eggers, H.- «Der Volksname...», p. 189. 
El diutisc ha de verse referido a la evolución del reino franco oriental «a partir de los componentes de tres grupos tribales de lenguas: los germanos del Mar del Norte, los de la zona Weser-Rin y los germanos del Elba, que en el curso de las migraciones se transforman en germanos alpinos» ${ }^{8}$.

Algo muy diferente había ocurrido a occidente del Rin. En esta zona el germánico franco es sólo el superestrato que se diluye poco a poco en los romances incipientes. La corte de Carlomagno desarrolla entre los años 813 y 840 una mezcla de latín y diutisc que se utiliza paralelamente a la lengua culta como lengua de la administración.

Lo mismo ocurre en la zona del franco-occidental y del langobardo en la Romania que se manifiesta en este hito del 842: Los juramentos de Estrasburgo (Straburger Eide): Cuando a la muerte de Ludovico Pío se reúnen sus hijos a repartirse el imperio y comprometerse a no luchar entre sí, advierten que las gentes a uno y otro lado del Rin hablan de forma tan distinta que no es posible un entendimiento directo entre ellos. Procede sin embargo que las promesas reales sean entendidas por el pueblo de la parte contraria y por ello, «sacramenta, quae subter notata sunt Lodhuvicus romana, Karolus uero teodisca lingua iuraverunt»?.

Conviene recalcar que la referencia del theodiscus latino es exclusivamente lingüística $y$, aunque imprecisa, abarca a un espacio superior al tribal que, de otra parte, se halla muy aquilatado léxicamente según la tribu concreta y a juzgar por los textos que aporta Grimm ${ }^{10}$ :

«gens Anglorum», «lingua Anglorum», «quod Alamanni dicunt, quod Bajuvarii dicunt»...

La expansión referencial se produce lentamente hacia usuarios y lugar de radicación de la lengua así definida durante el siglo IX y con más frecuencia en el X y XI: «gens teudisca», «terra theodisca» y ya en documentos no latinos, en distintas adjetivaciones a "gent, liute, man, volc, terre, lant...»

\section{El conflicto «deutsch»-«teutsch» del Mhd}

La ausencia del diutisc en los breves textos y glosas anteriores a 1050 -año que habitualmente se toma como inicio del Mhd.- da un extraordinario valor a su aparición en las glosas de Virgilio como diutischemo (Tegernsee) o como tutisscomo (Echternach) que, ya en el siglo XI, atestiguan la presencia de [t] inicial. Por la misma época se documenta repetidamente en Notker la forma con [d] inicial (in diusticûn) pero su validez debe ser relativizada a su personal código de consonantes iniciales.

${ }^{8}$ Moser, H.- Annalen der deutschen Sprache, Metzler, Stuttgar $1961^{4}$, p. 13.

9 Capitularia II, 171, cit. en Braune, W. \& Ebbinghaus, E.- Althochdeutsches Lesebuch. Niemeyer, Tübingen $1969^{14}$, p. 56.

${ }^{10}$ Grimm, J. op. cit. p. 5. 
Efectivamente y también en latín son frecuentes a partir del siglo IX las sustituciones de theodiscus por teutonicus con formas intermedias como p. ej. theotiscus. «Schon der alamannische mönch, welcher zwischen 884-887 die gesta Karoli verfaßte, beginnt zu schwanken: "teutonica sive theutisca lingua"11

La total sustitución de diutisc por tiutsch/teutsch en Mhd. no puede basarse únicamente en criterios lingüísticos, como son la falta inicial de soporte escrito y el verdader pantano ortográfico de los inicios documentales. Hay razones de tipo histórico, social e incluso psicológico. Si, como hemos visto, theodiscus/diutisc tiene fuertes connotaciones con el espacio y cultura francos, el obligado traslado del centro político de los Ludolfinger (los Otones) al este, a un espacio social no identificado con el concepto, se aprovecha para reformar sin pérdida de continuidad la imagen sonora e histórica de una palabra que ya tiene como referencia algo más que la lengua.

Teutsch (tutisc) será una forma adaptada e integrada de theodiscus y de teutonicus, pero no una evolución consonántica, imposible de $\bar{p}-->t$. La gran influencia del latín y de los clásicos juega también aquí su papel.

Ya Lucano hablaba del «furor teutonicus» y para el resto de la clasicidad también eran los teutones el prototipo de pueblo germánico:

«Zuerst von allen Germanen ist die antike Welt mit Angehörigen der westlichen Gruppe in Berührung gekommen. Das früheste Zeugnis dafür geht auf die Nordfahrt des Pytheas von Massilia im letzten Drittel des 4. Jahrhunderts v. Chr. zurück, der damals, u.a. die Teutonen als westgermanischen Stamm an der Nordseeküste kennengelernt hatte. (...) Der erste historisch faßbare dieser Westgermanischen Vorstöße (...) ist die Wanderung der Kimbern und Teutonen (...) zwischen 120 und 115 v. Chr., die (...) schließlich durch die Römer vernichtet wurden» ${ }^{12}$.

El soporte latino al nuevo gentilicio parece haber sido decisivo en la imposición de las formas con [t] inicial pues «teutonicus klang gelehrter als theodiscus, denn dies war doch unsrer sprache geschöpft, jenes aus der classischen, und im wahn, unser volksname rühre von den Teutonen her» ${ }^{13}$.

11 («Ya el monje alemánico que redacta entre 884-887 la "gesta Karoli” comienza a oscilar: "lengua "teutonica" o "theudisca"»). Grimm, J. op. cit. p. 9, comentando el pasaje de Monumenta Germaniae, Scriptores III, 735.

12 («De todos los germanos traba contacto el mundo antiguo en primer lugar con los pertenecientes al grupo occidental. El primer testimonio hay que buscarlo en el viaje al norte de Pytheas de Massilia en el último tercio del siblo IV a.C., quien conoció entonces, entre otros, a los teutones, tribu germánica occidental en la costa del Mar del Norte. (...) La primera incursión historicamente conocida de los germanos occidentales es la de los Cimbros y Teutones (...) entre el 120 y 115 a.C. (...) que fueron finalmente aniquilados por los romanos»). Krahe, H.- Germanische Sprachwissenschaft (I), Göschen-de Gruyter, Berlín 1969. passim $27-$ 28.

${ }^{13}$ («...teutonicus sonaba más culto que theodiscus, pues esta estaba creado de nuestra lengua mientras que aquel de la clásica y en la ilusión de que nuestro nombre nacional provenía de los teutones). Grimm, J. op. cit. p. 10. 
En todo caso las forma tiu(t)sch, teutsch y tütsch son las vigentes en Mhd. y Nhd. hasta el siglo XVIII y aún el XIX, épocas en que -dentro de la reflexión general sobre la lengua- se impone la razón etimológica que da paso a la forma deutsch actual.

Las formas propias de los dialectos bajo la cobertura del alemán, han sufrido distintas vicisitudes. El dialecto franco-mosela hablado en el Limburgo mantiene dutch desde sus orígenes carolingios; más al norte los neerlandeses oscilan entre dietsch en Brabante y Flandes y duutsch en el norte y este. Esta última forma es la que se impone finalmente en su variación gráfica y fonética duitsch [d its], de modo que en el siglo XVII aparece Nederduitsch como denominación de la lengua que en 1813 será oficial del estado holandés como Nederlandsch. De la antigua forma queda la denominación gentilicia en inglés: «Dutch» ${ }^{14}$.

La variante del estandard que habla la Suiza alemana mantiene la forma inicial en [t]. Su denominación en tüütsch, especialmente en las composiciones Schwyzertüütsch/Züüritüütsch.

\section{Las designaciones del alemán fuera de sus fronteras}

Indicaba al principio que las peculiaridades constitutivas del hecho alemán se reflejaban también en la diversidad con que las lenguas extranjeras se refieren al mismo. En este como en el caso que hacía de los teutones el prototipo de lo germánico, son las razones de vecindad o de contacto político y cultural las que determinan una u otra forma gentilicia.

Algunos vecinos del norte poseen formas derivadas de teutsch, como son tydsk en danés, tysk en sueco, tauta en letón y lituano, amén de las formas ya comentadas para los vecinos inmediatos.

El inglés se ha decantado por el término clásico y denomina german a quien no lo es más que él mismo, ya que anglos y sajones abandonan el continente entrado ya el siglo V p.C., después de que los romanos, genéricamente, los incluyesen, tras sus primeros contactos, en el nombre afable de germani.

Pero el buen número de seguidores del inglés consigue generalizar el uso de este término en substitución del que empleaban antes del siglo XVII: dutch. Germano y germánico son adoptados por el griego moderno y, en general, por todas las lenguas como hiperónimo poco matizado de lo alemán.

También las lenguas románicas han incorporado denominaciones sesgadas para el hecho alemán. La lengua francesa -que también recibe su bautizo de un grupo tribal, aunque sea el más representativo y fuerte- cuenta en sus orígenes con el adjetivo afr. tieis/Tyois para los francos orientales, mientras que aplica el de alemant a los del sur.

14 Datos sobre el neerlandés en Hutterer, Claus Jürgen.- Die germanischen Sprachen. Ihre Geschichte in Grundzügen. Akadémiai Kiadb, Budapest 1975, p. 268. 
También el español diferencia(ba) entre tudesco ${ }^{15}$, adscribiéndolo imprecisamente al norte alemán (quizá por las relaciones bélicas habidas con los Países Bajos), y alemán, en sentido genérico.

Sin embargo, el concepto de alemán filológica y étnicamente sólo puede ser aceptado como una sinécdoque que responde a la razón de vecindad ya citada. Los alamanes -a quienes denominaré así según una de sus múltiples grafías-aparecen imprecisamente en los siglos anteriores a la era cristiana disputando el espacio fronterizo romano y desaparecen o son integrados por el empuje de los godos sobre el año 490 p.C. Tras su desaparición pervive el gentilicio como denominación toponímica y como referencia dialectal. Los alamanes no habían utilizado los métodos violentos que ya caracterizaban a teutones, ambrones y cimbros y que posteriormente harían suyos los godos y hunos en su penetración en el imperio romano, sino que llevan a cabo un proceso diferente, mucho más temprano y constante. Mientras los godos se establecían en el Mar Negro, los alamanes «habían estado durante dos siglos haciendo intentonas de ganar más terreno» ${ }^{16}$. Hasta comienzos del siglo IV p.C. habían conseguido, de forma progresiva, rebasar el Limes y a partir de ahí «desde sus territorios situados entre le lago de Constanza y la curva del Rin (junto a Basilea) (...) consiguen poner pie firme al oeste y sur del Rin (455-480), separaron Alsacia y la Suiza septentrional de la Romania y se asentaron allí. Este avance hizo que la penetrante cuña de la ocupación germánica se clavara (...) en uno de los puntos más sensibles del límite del Imperio» ${ }^{17}$, corta las comunicaciones entre la Galia oriental y la Raetia y «debió ser la causa inmediata de la separación lingüística del retorománico» ${ }^{17}$.

\section{Penetración alemánica en la Raetia}

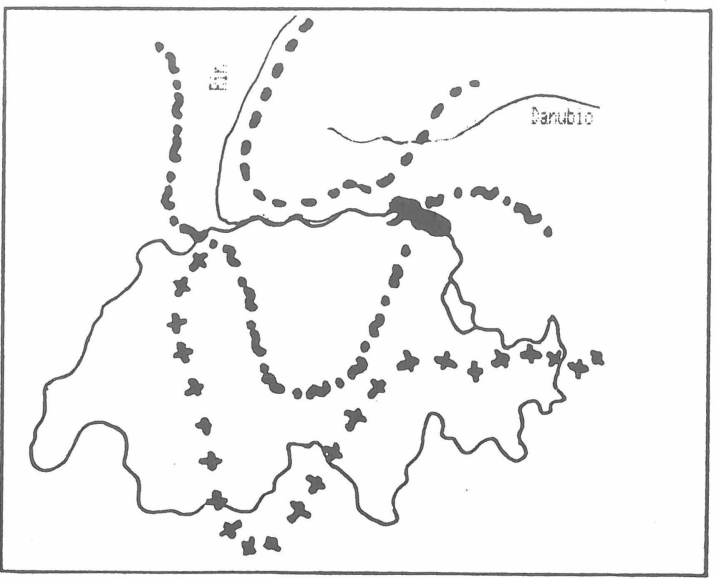

- . - - Hasta el 260 p. C.

$\sim$. . . Hasta el 460 p. C.

++++ Del siglo IX al XIII

Silueteado de la frontera suiza actual

15 «Ad. Natural de cierto país de Alemania en la Sajonia inferior (...) por extensión, alemán» en Casares, Julio.- Diccionario ideológico de la lengua española. G. Gili, Barcelona, $1959^{2}$.

16 Wartburg, M. von.-La fragmentación lingüística de la Romania, Ed. Gredos, Madrid 1971², pág. 83.

${ }^{17}$ Ibidem págs. 83 y 84. 
Esta es mi opinión la causa de que el apellido alamán sea de mayor pregnancia y se haya conservado para gran parte de la Romania como denominador genérico de los germanos no asimilados, pues, por ejemplo al este de la región alemánica (actual BadenWürttemberg), en lo que hoy es Baviera, «persistió el dominio romano durante dos siglos y medio más» que en la curva del Rin $\mathrm{y}$, aunque los territorios de los bayúvaros «no fueron romanizados en su totalidad, una capa superficial románica imprimió, sin duda, cierto carácter latino al país» ${ }^{18}$, carácter que aún hoy tiene algunas formas de pervivencia.

Pero no toda la Romania es uniforme en esta elección; el italiano es quien adopta la más acorde a la utilizada por los propios interesados: Tedesco es el que habita la antigua Germania romana, que conserva -siempre en italiano- esta denominación como país. Privan aquí sobre las razones de vecindad la clasicidad teutónica y posiblemente la dominación y presencia directa de los alemanes durante siglos en el norte de la actual Italia.

\section{Abreviaturas}

$\begin{array}{llll}\text { afr. } & \text { francés antiguo. } & \text { germ. } & \text { germánico. } \\ \text { afries. } & \text { frisio antiguo. } & \text { got. } & \text { gótico. } \\ \text { ags. } & \text { anglosajón. } & \text { mhd. } & \text { alto alemán medio. } \\ \text { ahd. } & \text { antiguo alto alemán. } & \text { nhd. } & \text { alto alemán moderno. } \\ \text { as. } & \text { sajón antiguo. } & * & \text { formas no documentadas. }\end{array}$

\section{Bibliografía}

Braune, Wilhelm \& Ebbinghaus, Ernst.- Althochdeutsches Lesebuch. Niemeyer, Tübingen $1960^{14}$.

Eggers, Hans (ed)- Der Volksname Deutsch, Wissenschaftliche Buchgesellschaft, Darmstadt 1970.

Freund, Michael.- Deutsche Geschichte, Bertelsmann Lexikon Verlag; Gütersloh-Berlín, 1974.

Hutterer, Claus Jürgen.- Die germanischen Sprachen. Ihre Geschichte in Grundzügen, Akadémiai Kiadó, Budapest 1975.

Krahe, Hans.- Germanische Sprachwissenschaft (I), Göschen-de Gruyter, Berlín 1969.

${ }^{18}$ Wartburg, M. op. cit. p. 78. 
Moser, Hugo.- Annalen der deutschen Sprache.- Metzler 5, Stuttgart $1961^{4}$.

Tennbrock, R.H.- Geschichte Deutschlands, Hueber, München $1968^{2}$.

Tschirch, Fritz.- Geschichte der deutschen Sprache (I), Erich Schmidt, Berlín $1983^{3}$.

Wartburg, Walther v.- La fragmentación lingüistica de la Romania, Gredos, Madrid 19712. 
